\title{
'Shaping the Future', Black History and Diversity: Teacher perceptions and implications for curriculum development
}

\section{Paul Bracey University of Northampton, Northampton. UK}

\begin{abstract}
This study provides an evaluation of history subject leader's perceptions of a project called 'Shaping the Future', together with their attitudes towards Black History and Diversity. It found that Primary Subject Leaders were less likely to attach importance to these dimensions that their counterparts in secondary schools, while only a small minority of subject leaders made use of the project. Nevertheless, the findings provided insights into how some subject leaders used them as threads or within topics in their curriculum. The study argues that this provides a model for developing Black History as a means understanding the past which is applicable to meeting the needs of all children.
\end{abstract}

Keywords: Diversity, Black History, teacher perceptions, 'Big Picture’ History

\section{Introduction}

This paper considers teacher perceptions of Black History following the implementation of a Heritage Lottery funded curriculum project called Shaping the Future, which developed school curriculum resources related to Black History for children from the ages of 5-14. The study focused on two research questions: What were History subject leader's perceptions of Black History? What was the impact of Shaping the Future? Findings from history subject leaders working in both primary (5-11 years) and early secondary (11-14 years) provide useful comparative insights. The discussion based on them will be considered with respect to their implications for curriculum development in primary schools. Although the focus of the study relates to Black History, it is based on the premise that aspects of diversity such as gender, religion and class, together with white ethnicities and different geographical localities, also contribute towards developing an holistic understanding of the past.

Shaping the Future was developed in Northamptonshire, a county in Eastern England where non-white communities accounted for only $8.5 \%$ (NCC, 20I1) of the population. Gain 
and George (1999) argued that multicultural education is restricted to schools serving multicultural communities, whilst Grosvenor and Myers (2001) reported that teachers in some rural counties felt unable to prepare their pupils for life in a multicultural society. Consequently, Northamptonshire represented the type of locality which one might expect to find teachers resistant to teaching multicultural topics. Research undertaken by Siblon (2005) in Northamptonshire found that $80 \%$ of subject leaders claimed to have little or no knowledge of Black History, $78 \%$ said that there were no teaching resources and $74 \%$ rarely or never taught Black History. It remaines to be seen whether this reflected resistance, confidence or lack of expertise. However, Siblon's (2005) research provided a case for developing Black History materials, which was used to support the Heritage Lottery bid application which led to the 'Shaping the Future' project. The impact of the project together with teacher perceptions of Black History will be evaluated, together with the implications of National Curriculum 2014 in England (DfE, 2013) for the project materials.

\section{The Social and Policy Context for 'Shaping the Future'}

The treatment of majority and minority groups in contemporary society has been related to perceptions of their significance in the past. Berger and Lorenz (2008) argued that National Histories, the dominant genre of history writing in Europe: ‘...often underpinned exclusive, xenophobic and intolerant national identities which were quick to exclude, isolate, persecute and even eradicate those who were represented as not belonging to the (typically homogenous) national community' (Berger and Lorenz, 2008,550). This perspective resonates with issues which have confronted the Black community in Britain. The Macpherson Report (1999) which investigated the murder of a Black teenager Stephen Lawrence and The Race Relations Act (2000) raised issues associated with institutional racism. They set out to challenge this through a range of recommendations such as amending the National Curriculum to include people from a wide range of ethnic and cultural groups and putting strategies in place to deal with racism. Particular reference was made to the implementation of this policy in areas dominated by white communities. Macpherson's challenge to racism was regarded as exceptional with respect to the positive response which it received, but it was subsequently undermined by developments which reflected dominant white majority interests (Grosvenor and Myers, 2001; Gillborn, 2008). The Parekh Report (2000), submitted barely twelve months after Macpherson, attempted to provide an inclusive history of Britain but was subjected to an extremely hostile response from the popular press 
(Johnson, 2000). After 9/11, race related disturbances in 2001 and the $7 / 7$ bombings in London, a policy of community cohesion sought to promote common values and relations between different backgrounds. However, Gillborn (2008) argued that the overwhelming weight of social and educational policy associated with this failed because 'it ...pandered to the White racist sentiment and left the principle race inequalities untouched'(Gillborn, 2008, 89). Mycock argued that the period following $9 / 11$ was characterised by political imperatives emphasising social inclusion based on common British values where there was '...little acknowledgement of how empire and Commonwealth can also contribute to more generous and plural interpretations of Britishness (Mycock, 2010,196).

'Shaping the Future' curriculum materials were produced during 2008-10 at a time when community cohesion was being promoted in the school curriculum. Grosvenor and Myers (2001) observed that the content of England's History National Curriculum (Department for Education and Employment/Qualification and Curriculum Authority, 1999) at the start of the millennium focused on traditional white history subject matter, despite a declared commitment to teaching about 'diverse culture' and 'diverse' heritages. Another Primary History Curriculum which included reference 'to identities, communities, together with the movement and settlement of people at different times' (Qualification and Curriculum Development Agency 2010 p.38; p.41) was due for implementation by the Labour Party in 2011, but was abandoned following a change of government in May 2010. Consequently, the QCA/DfE (1999) National Curriculum remained in place in local authority primary schools until the current curriculum was introduced in 2014 ( Department for Education, 2013). This was in variance with the secondary curriculum where diversity was promoted through links between citizenship and history following The Curriculum Review on Diversity and Citizenship (2007) and the Secondary National Curriculum introduced in 2008 (Qualification and Curriculum Agency, 2007). The teaching of diversity was strengthened at Key Stage 3 (11-14) both as a concept and substantive content. Black History contributed to themes such as migration, pre colonial civilisations and the Transatlantic Slave Trade.

The evaluation of Shaping the Future which provides the basis for this paper was undertaken inthe period after a Conservative/Liberal Coalition Government came into power in 2010. This has subsequently been followed by the election of a Conservative Government in 2015. David Cameron, the Conservative Leader of the Coalition government argued that multiculturalism had failed Britain (Helm, Taylor and Davis, 2011). More recently, 
government concerns have been reflected in the Department for Education's advice for the promotion of British Values through Spiritual, Moral, Social and Cultural Education which stressed the importance of enabling students to acquire an appreciation of and respect for their own and other cultures and identifying and combating discrimination. (DfE, 2014). However, although the National Curriculum which was introduced in 2014 made reference to diversity as one of the purposes for studying history it did not relate to it in any key stage statement. The History National Curriculum made reference to Rosa Parks and Mary Seacole as significant individuals in the past who have contributed to national and international achievements at Key Stage 1, Benin at Key Stage 2, together with the Transatlantic Slave, its effects at Key Stage 3 but did not require that they should be taught.

\section{Black History, diversity and teaching about the past: Contested perspectives of History Educators}

Shaping the Future challenges traditional approaches to the past dominated by the white majority culture which inevitably relates to contested views about what should be taught in classrooms. McGovern (2007) argued for a traditional approach to the history curriculum which emphasised fostering national pride. Similarly, Lang (2011) argued that teaching Asian and Caribbean history to children from different ethnic backgrounds should be replaced by learning about the national past through exploring how Nelson and Wellington became cult heroes. Claire provided a contrasting perspective and argued that history should include 'female or male, and middle, upper and working class, and from an ethnic minority or the dominant 'white' English group in British society' (Claire 1999, 10). Some history educators have raised issues associated with diversity the structural integrity of the subject. Bradshaw (2009) was critical about the way in diversity was defined in the revised Key Stage 3 History Curriculum for England (DfES, 2007),

'It is interesting that 'diversity' immediately brings to mind for many people the notion of non-British history, or the history of diverse ethnic, cultural or religious groups, or a particular emphasis on previously under-represented groups-the working class. Perhaps it should...It is necessary to reclaim the term 'diversity' from the politicians in order to bring out its meaning as the richness of the historical tapestry, the small stories, the exceptions, the variety of the past in all its fullness (Bradshaw 2009, 5)'. 
Bradshaw was concerned with developing an understanding of diversity as a historical concept rather than as a means of addressing contemporary issues. Corfield's (2009) definition of 'Big Picture History' goes beyond the above issues by defining how the past should be understood which appreciates the place of diversity within it. Her definition of 'Big Picture History' characterised learning about the past as an unfolding story which was not reduced to ideological, religious, nationalist, sexist, hierarchical, classist or mythical accounts. She argued for a coherent framework of the past which allowed for different cultural traditions and a sense of common humanity -showing diversities within, as well as between cultures and the need to relate it to time. Although Shaping the Future related explicitly to diversity, the discussion section of this paper will recommend that 'Big Picture History' provides an essential framework in which to develop Black History.

Shaping the Future set out to address the need for a Black History dimension in the curriculum which resonated with the schools in Northamptonshire, although the materials could be used in other areas. It provided curriculum packs for schools related to the following themes:

Theme 1: 'From Slavery to Emancipation' (Gove-Humphries, 2007);

Theme 2: 'Walter Tull: Sport, War and Challenging Adversity’ (Claire, 2007);

Theme 3: 'Representations of Empire: Learning through Objects' (Bracey, Martin, and Burdett, 2011);

Theme 4: 'Living Memories' (Gove-Humphries and Haynes, 2008);

Theme 5: 'Northamptonshire in Global Context' (Bracey, Alloway, Curtis and Smart, 2009).

The first theme From Slavery to Emancipation' (Gove-Humphries, 2007) dealt with the most clearly identified topic associated with Black History and was intended for Key Stage 3 (1114). The resource drew upon Traille's (2007) study which identified issues with restricting the transatlantic slave Trade to the experiences of slaves as victims. The pack explored slavery in different societies, together with pre-colonial Africa and the role of Black people in challenging it. Shaping the Future was also based on the premise that Black History should not be restricted to the study of slavery. The remaining themes provided aspects of Black History which could be integrated into different parts of the curriculum. All of the remaining themes were appropriate for Key Stage 2 (7-11) as well as Key Stage 3. The theme Walter Tull: Sport, War and Challenging Adversity included curriculum resource packs for Key 
Stage 1(5-7) as well as Key Stages 2 and 3. Walter Tull was a famous local footballer and the first Black Officer in World War 1. Two curriculum packs based on his experiences were sent to all primary and secondary schools in the county (for primary schools the first pack was appropriate for Key Stage 1 and the second for Key Stage 2) as a means of promoting the project. This was potentially problematic as his story was untypical of the minority experience (Kushner, 2006). However, it was felt that the pack could serve to encourage teachers to adopt the remaining more broadly based resources. Themes 1 and 5 could be freely downloaded from the Northamptonshire Black History Association website and packs 3 and 4 were available for purchase. 'Shaping the Future' resources were promoted by sending fliers, twilight workshops and events aimed at local teachers. The Heritage Lottery bid also supported the publication of a local history textbook which demonstrated that Northamptonshire had links with Black History dimension which stretched back to the Middle Ages (Ali et al, 2008)

\section{Methodology}

What were primary history subject leader perceptions of Black History? What was the impact of Shaping the Future? These research questions provided a focus for this investigation. The location of the study in an English County serving largely white communities had implications for the findings compared with schools serving a multicultural context. Consequently, it was regarded as a case study, from which 'fuzzy generalisations' could emerge and, at some future point, be compared with studies of teacher perceptions elsewhere (Bassey, 1999; Yin, 2009). The investigation was based on the belief that subject leaders have a critical role in developing the history curriculum. This view is supported by Field, Holden and Lawlor's (2000) argument, that subject leaders in both primary and secondary schools have become important since the introduction of the National Curriculum, Ofsted and the National Leadership Standards. An insight into the reasons for this is provided by Borko, Davinroy, Bliem and Combo's (2004) argument that the beliefs and practices of individual teachers could influence the way in which they responded to implementing change.

Banks, Leach and Moon (2005) argued that teacher subject knowledge consists of subject knowledge related to the academic nature of their subject, school knowledge which transports it to the school context and pedagogic knowledge which interact with each other in order to bring their professional knowledge into being. They stated: 
'.. at the heart of this dynamic process are the personal constructs of the teacher, a complex amalgam of past knowledge, experience of learning, a personal view of what constitutes 'good teaching' and a belief in the purposes of the subject'. (Banks, Leach \& Moon, 2005,336)

By implication such factors as experience and values which teachers bring to their work or have been exposed to in the past could affect how they far they support or approach a Black History dimension in the curriculum. The significance of teacher perceptions and values was demonstrated in Kitson and McCully's (2005) study of teachers in Northern Ireland in which they categorised teachers who refrained from teaching controversial issues as 'avoiders', those who taught them through historical processes or topics which do not directly affect pupils as 'containers' and others as 'risk takers'. Whilst the context of Kitson and McCully's study was different from that of the present study it was assumed that a subject leader's experience and values would be significant when considering their perception of Black History. This said, subject leaders are subject to constraints such as managerial imperatives which can impede their opportunities for curriculum development (Gunterer and Thomson, 2009; Tang and Chio, 2009; Codd, 2010). Shaping the Future was developed for primary and lower secondary age children. A comparison of its impact in the two sectors does justice to assessing the impact of the project and also provides an opportunity to highlight similarities and differences in the way that subject leaders in primary and secondary schools responded to it. More broadly it provides insights into how far subject leader perceptions of Black History and diversity were affected by the teaching phase or the location of the schools. However, it is important to appreciate the differences between the context in which primary subject leaders work compared to their counterparts in secondary schools which could impact on their perceptions. Black History was defined more explicitly in the History programme of study at Key Stage 3 (QCA, 2007) compared to the National Curriculum (DfEE, 1999) in Primary schools. The way in which teachers in Primary Schools typically teach to a specific year group has many advantages, not least the way that it enables them to focus on the needs of each child. However, it has been argued that with this organisational structure, the scope for history subject leaders to implement changes in this context, could be adversely affected by insufficient time, resources or expertise to perform their role effectively (QCA, 2004; Ofsted,2011). 
Two research methods were adopted: questionnaires and semi-structured interviews. The research methods and structure of questions were based on the approach used in a previous study which explored an Irish dimension in the curriculum (Bracey, 2010). The questions were piloted with volunteers outside Northamptonshire. Questionnaires were sent to all history subject leaders in primary and secondary schools in the county. The first part of the questionnaire focused on teacher perceptions of different dimensions in the curriculum. Subject leaders were asked to rate the importance of dimensions such as English History, British History, Women's History, Scottish History, Welsh History, Irish History and diversity, alongside Black History. The second part of the questionnaire focused more explicitly on the teachers' responses to Shaping the Future, including their perceptions of its impact. Interviews followed the same structure as the questionnaire but provided opportunities for subject leaders to elaborate on the extent to which they believed Black History and 'Shaping the Future' influenced the ways in which they taught children about the past.

History subject leaders representing 29\% (74/255) of primary and 39\% (17/44) of secondary schools in the county responded to the questionnaire. For comparative purposes the raw data was converted to percentages, although it is appropriate to appreciate that the number of primary respondents was over four times greater than secondary. Interviews were undertaken with twenty subject leaders of whom ten (three secondary and seven primary) used Shaping the Future and ten (four secondary and six primary) had not used it. All interviewees were volunteers, having completed a consent form in the questionnaire. Seven secondary subject leaders volunteered and all of them were interviewed. Over twenty primary subject leaders volunteered and the first seven who used the resources and the first six who did not use them were contacted. This approach was taken in order to compare a fairly equal number of subject leaders who had used the resources with those who had not. Ethical adherence was made to BERA (2011), and questionnaire and interview requests indicated the purpose of the research, guaranteed anonymity to respondents and their institution, together the opportunity to withdraw from the research process. A number of issues associated with the study had implications for the reliability of conclusions which could be drawn from it. Firstly, all the interviewees were white. Gillborn (2008) has argued that white teachers are unlikely to deconstruct and challenge the privileging of a white perspective and it remained to be seen how far the findings supported this premise. Secondly, I had been involved in developing Shaping the Future and was concerned that my involvement in its development might 
influence responses to the questionnaires and interviews. This was addressed by providing a range of dimensions for respondents to address and ensuring that questions were open ended, without obvious right and wrong answers.

\section{Findings}

When interviewees were asked to define diversity they typically made reference to how it related to the way in which children were encouraged to treat other people. One primary history subject leader said teaching about diversity enabled them to 'give children different experiences and different ideas and values that other people have because we find that our children are very closed minded'. Other references to diversity included 'making children feel valued', understanding that 'people have different values and beliefs' as well as, 'the need to challenge racism'. Three primary subject leaders undertook specific measures to address racism such as twinning with schools serving different communities. The following comment is an example of how an interviewee related this to their teaching:

I think it's just, there's obviously the cultural side isn't there, diversity of culture and race, and then I suppose you could look at the diversity of how you treat the curriculum couldn't you as well.

Secondary interviewees tended to raise more problematic issues associated with diversity. One secondary subject leader was critical about the way in which diversity had been applied to history in the National Curriculum, commenting:

'I suppose to be politically correct I would say that's very important. Diversity seems to be like the new buzz word, particularly in history. I'd say I'd never seen it as... diversity isn't a word that naturally comes out when you're talking to the kids about something'.

There is a distinction between this interviewee's use of pejorative descriptions of diversity such as 'I suppose to be politically correct' and 'the new buzz word' and a perception that diversity is alien to the nature of the subject, revealed in the statement '...diversity isn't a word that naturally comes out.' This subject leader was the only interviewee who specifically 
linked their definition of diversity to history but their perception resonates with concerns raised by Bradshaw (2009).

However, this history subject leader was exceptional amongst the interviewees in taking a critical stance. A particularly salient comment was made by a secondary subject leader who claimed that their school's location and the white community which it served was an issue which they ought to address by encouraging children to appreciate that:

'...we're all different people ... it's not just about race, it's about the fact that there is diversity amongst white people as much as there is diversity between black and white people and [our] children aren't particularly tolerant ....and they do have a lot of prejudice and stereotype and so for us diversity really is about us trying to break that down.'.

The remaining secondary subject leader interviewees made reference to diversity AS providing the means to challenge ethnocentric attitudes held by some pupils in their school. One interviewee drew particular attention to their local context: '...we've discussed it several times, about the way in which the lack of diversity within our student body requires us to approach certain topics and to actually try and challenge the perspectives that come from that'.

Black History represents one aspect of diversity and it is interesting to see perceptions of its importance compared to other dimensions. Table 1 compares history subject leader perceptions of Black History with other dimensions associated with diversity. It also shows the importance which history subject leaders attached to diversity in general.

\section{Table 1: History Subject Leader perceptions of Black History compared with other dimensions.}

Thirty percent of primary history subject leaders included Black History diversity at Key Stage 1 whereas $50 \%$ included Diversity. Only $25 \%$ of primary history teachers included Black History at Key Stage 2 whereas 33\% included diversity. However, 100\% of secondary teachers included Both Black History and diversity at Key Stage 3. However, it is interesting 
to note that only $24 \%$ regarded Black History at important at Key Stage 3, which compared with 3\% at Key Stage 1 and 7\% at Key Stage. However, 25\% of primary leaders considered diversity important at Key Stage 1 which rose to 33\% at Key Stage 2, compared with only $13 \%$ of secondary respondents. When comparing Black History with other dimensions it was evident from both primary and secondary respondents that diversity associated with social class, women and local dimensions were more likely to be included Black History. However, Scottish, Welsh and Irish dimensions were less likely to be included. The importance of teaching English and British dimensions was rated far more highly than the importance of teaching other dimensions. Perhaps a more fruitful line of enquiry is to consider the impact of Shaping the Future.

\section{Teaching of Black History by Subject leaders who did not use Shaping the Future.}

Table 2 indicates that only a minority of history subject leaders used 'Shaping the Future'. A high proportion indicated that they had not received the Walter Tull resource packs.

\section{Table 2: History Subject Leader responses to Shaping the Future}

Interviewees gave a number of reasons to explain why they had not adopted 'Shaping the Future'. Three history subject leaders (one secondary and two primary) said that they had not received the packs, four (two primary and two secondary) had forgotten about them, two (one secondary and one primary) said that they had gone to another subject leader in the school. One primary history subject leader interviewee felt that they could not introduce resources because of whole school planning constraints which inhibited opportunities to innovate. This did not of course mean that only history subject leaders who used Shaping the Future taught Black History.

Evidence from ten semi-structured interviews with history subject leaders who had not used Shaping the Future showed a range of perceptions towards Black History which was sometimes linked to other aspects of diversity. Three primary subject leaders either did not include Black History in their curriculum or restricted it to teaching about Mary Seacole, which raises issues about typicality (Kushner, 2006). However, one primary subject leader 
made reference to both diversity and Black History when teaching Africa as a topic with her Key Stage 1 class:

'I think we've tried very hard to make it more diverse if you like, or to look at the opportunities to make it so, so for instance again, looking at Africa, looking at Mandela... trying to avoid some of the misconceptions that the children have'.

This history subject leader's comment appears to have been part of her broader commitment towards challenging stereotype images of Africa. Arguably, she had identified a strand in teaching Black History which reflected her own knowledge and beliefs. The four secondary subject leaders who had not used Shaping the Future taught Black History through the transatlantic slave trade, although this was contained within a topic on Black Peoples of America. However, one secondary subject leader developed diversity throughout much of Key Stage 3 which incorporated Black History. For example, by using 'The Titanic' as a focus for a theme they encompassed different aspects of diversity including Irish migration, social class, the Suffragettes and Black History, together with Ghandi. Elsewhere in their course this subject leader taught Guy Fawkes and the Gunpowder Plot as a local study, using it as means for exploring issues associated with religious diversity and modern day terrorism.

\section{Subject leaders who used Shaping the Future to develop Black History.}

The following will consider on how far the project was used as well as the extent to which subject leaders related it to a broader consideration of Black History. The Walter Tull pack (Claire, 2007) was used more extensively than other resources. All schools were sent two packs related to either Key Stage 1 and $2 / 3$ or $2 / 3$ and 3. At least one Walter Tull curriculum pack (Claire, 2007) was adopted by $29 \%$ of primary school subject leader respondents compared with $24 \%$ of those from secondary schools. $19 \%$ of primary subject leaders said that they used the Walter Tull storybook which accompanied the Key Stage 1 pack and 7\% indicated that they used the 'Living Memories pack' (Gove-Humphries and Haynes, 2008). The following section focuses on the perceptions of those subject leaders who used Shaping the Future and how this related to their perception of Black History.

Interviews with ten subject leaders who made use of the resources indicated that, with the exception of one teacher all interviewees taught in schools where white children.One primary 
history subject leader used the Walter Tull pack because she believed that his career as a footballer would motivate boys to want to learn about History. Two primary interviewees used the pack as a focus for activities during whole school 'Diversity Weeks'. One subject leader related a study of Black American servicemen to the children's work on World War 2. Another history subject leader used the Walter Tull curriculum pack as a stimulus for studying other diversity related topics including Ghandi, the Suffragettes and the women's rights movement in the 1970s. A third primary subject leader used the pack to provide a local dimension within their International Primary Curriculum (n.d), a commercially produced cross curricular course which was designed to enable schools to teach a global dimension in the curriculum. This interviewee reflected:

'...when we were looking at Black history [we were] looking at ...role models. I think the reason Walter Tull was quite powerful [was] because [he was] a local hero. It looks at the diversity element... children can easily relate to that person... the mere fact that he lives a stone's throw away, that was really hard hitting'.

Here the interviewee was drawing links between Black History and local history. However, their reference to using Tull as a 'role model' suggests that their reasons for teaching it were not confined to history. The way in which these primary subject leaders related the packs to broader themes was also evident in interviews with secondary subject leaders. One secondary subject leader used the Walter Tull curriculum pack (Claire, 2007) as an introduction to their study of the trenches in World War 1. Another secondary interviewee used the Slavery to Emancipation pack (Gove-Humphries, 2007) to ensure that pupils explored how black and white people were involved in challenging slavery, together with the Walter Tull curriculum pack during a one day event led by a representative from Northamptonshire Black History Association. Regardless of whether they worked in primary or secondary schools, these subject leaders showed how they had used 'Shaping the Future' to broaden their approach to specific history topics and, in some cases, were beginning to make links with other history topics or themes.

Two interviewees - one primary and one secondary - developed Black History as an important dimension in their courses. The primary history subject leader was not typical of teachers in the study in that they taught in a school which included a high proportion of 
children from Black communities and refugees from Eastern Europe and Somalia. The Walter Tull and 'Living Memories' (Gove-Humphries and Haynes, 2008) resource packs were used as stimuli for a topic called 'Coming to Britain'. The 'Living Memories' resource (GoveHumphries and Haynes, 2008), which was based on the experiences of Black people coming to Britain in the 1950s and 1960s, provided a basis for children to explore and share their own histories. However, the history subject leader also saw this as part of a broader understanding of diversity which included the ethnicity of white children and social class which they related to a local study of the 'Five Boroughs' as part of a wider topic about the Victorians. Overall, the approach used here was to relate Black History to different topics related to diversity. The secondary history subject leader interviewee was more typical of this study in that they taught in a large town serving a predominantly white community. The Walter Tull pack was used as a focus for studying World War 1: 'We use [the Walter Tull pack] to link into World War I ... and then to look at the impact of war on Black people and on colonies and how that then made them feel.' This was part of a thread in their course which included slavery, Empire, World War 1 and 2, the collapse of Empire and post war migration from the West Indies to Britain. Elsewhere in this secondary subject leader's course, the 2010 World Cup provided a focus for studying aspects of Black History associated with civil rights in America and South Africa.

\section{Discussion}

\section{What were history subject leader perceptions of Black History? What were their perceptions of the impact of Shaping the Future?}

Virtually all primary and secondary interviewees made positive comments about the value of teaching diversity in challenging issues such as racism. However, this was not reflected in most teacher perceptions of Black History. Only, small proportion of primary subject leaders indicated that they taught or considered Black History compared with their secondary counterparts. Fewer primary than secondary subject leaders said that they included diversity. This may reflect the fact that although the Primary History Curriculum (/DfEE/QCA, 1999) made reference to 'social, cultural and ethnic diversity' it was emphasised as both a concept and content requirement at Key Stage 3 (QCA, 2007). However, a higher proportion of primary than secondary subject leaders regarded diversity as important. In some cases this 
may reflect its contribution to whole school based 'Diversity Weeks' events. However, the fact that only a minority of subject leaders in either primary or secondary schools considered Black History or diversity to be important in their teaching suggests that they were primarily concerned with the history of our dominant white culture (Gillborn, 2008).

However, the study provided useful insights into the way in which subject leaders had developed Black History and related it to diversity. This was not exclusively confined to those who used Shaping the Future. Most primary interviewees who used the packs related them to broader themes associated with diversity. Some primary and secondary subject leaders used the packs to enhance existing topics. A small number of subject leaders used Shaping the Future as part of a broadly based approach to the history curriculum which gave due consideration to both Black History and diversity. The overall impression is that the attitudes and values of the individual subject leader rather than whether they taught in a primary or secondary school influenced their approach towards teaching Black History.

\section{Building on 'Shaping the Future' and developing Black History in the context of National Curriculum 2014: Challenge or opportunity?}

In response to the findings for this study more Shaping the Future resources, including the Walter Tull packs have been made freely available online. It has also been possible to promote it through teacher publications, conferences and within Initial Teacher Education. However, one conclusion which can be drawn from the findings is that making resources available does not guarantee that they will have a widespread impact. At the same time opportunities for explicitly promoting Black History are more challenging in 2015 than when Shaping the Future was introduced. The National History Curriculum introduced for English schools in 2014 (DfE, 2013) includes reference to the 'diversity of societies and relationships between different groups' (DfE, 2013, 189) as one of the purposes of history. However, the term does not appear elsewhere in the document and there is no specific requirement to include Black History or ethnic and cultural diversity, although the document does include non statutory examples. Consequently, it could be argued that this makes it difficult to make a case for teaching Black History or introduce projects like Shaping the Future.

Can the case for teaching Black History and diversity be strengthened? This could be done by emphasising the way in which it relates to the history curriculum as a whole. The History 
Curriculum introduced in 2014 requires a holistic approach to the past which includes making links between local, national and world history in order to provide a coherent understanding of the past. This relates to recent literature supporting 'Big Picture History'. Corfield's (2009) model for developing 'Big Picture History' argued that it should provide a broadly based narrative which includes a range of different perspectives and contributions rather than a national and ethnocentric perception of the past. Within this framework it is possible to make a case for teaching Black History as one of many stands which contribute to both our understanding of the past and different perspectives within it. However, it is necessary to go beyond making a case for including Black History and explicitly demonstrate how it relates to developing this broadly based understanding of the past.

The findings indicate that some primary and secondary subject leaders related Black History topics or Shaping the Future to broader themes or topics which resonate with 'Big Picture History. For example, Walter Tull was used as a focus by some subject leaders as an introduction to studying the trenches. This approach can be related to 'Big Picture History' in a way that is appropriate to the age of the children. At Key Stage 2 Tull's life can be related to an event since 1066, or a local study. A study of his experiences can be followed by questions such as - Would soldiers from our locality recognise Walter's story? Who else was involved in the war? Where did they come from? What were their lives like? (Bracey, 2015). Similarly, a study of recent migrant experiences through the Living Memories pack provides an opportunity to relate a study of the Romans, Anglo-Saxons and Vikings at Key Stage 2 to an unfolding story of different people who have migrated to Britain, by providing the opportunity to compare and contrasts the different experiences of people over time.

In conclusion, 'Shaping the Future' provided opportunities which were used effectively by some subject leaders but was limited. This reflects the difficulties faced when promoting minority histories against our dominant white culture, a problem which is greater outside multicultural neighbourhoods. Although, primary school subject leaders were less likely than their secondary counterparts to include Black History, the attitude and values of individual teachers, rather than age phase, was more important amongst those who innovated. This can be built on and developed by focusing on the in which children relate Black History to the process by which they develop a broadly based 'Big Picture' of the past.

\section{References}


Ali, I. Babb, M. Bracher, T. Brownwell, J. Bush, J. Leiston, R. Mohammed,W. Madu, A. Morgan, M, Narh, L, Palmer-Smith, D, Pounds,C. Sandos, A. Taylor, N. and Ukargbu,V. 2008. Sharing the Past. Northamptonshire Black History. Northampton: Northamptonshire Black History Association

Banks, F; Leach, J; Moon, B. 2005. 'Extract from New Understandings of teachers' pedagogic knowledge.' The Curriculum Journal. 16 (3):331-40

Bassey, M. 1999. Case study research in educational settings. Buckingham: Open University Press

BERA .2011. Ethical Guidelines for Educational Research. London: British Educational Research Association.

Berger, S and C. Lorenze, 2008. The Contested Nation. Ethnicity, Class, Religion and Gender in National Histories. Basingstoke: Palgrave MacMillan

Bracey, P., D. Martin, and S. Burdett, 2011. Representations of Empire. Learning through Objects (Key Stages 2 and 3) Northampton: Northampton Black History Association. (Second Edition). http:// www.northant-black-history.org.uk Bracey, P., A. Alloway, J. Curtis, and D. Smart. 2009. Northamptonshire in a Global Context. Mainstreaming Black History in the Curriculum (Key Stages 2/ Key Stage 3. Northampton: Northamptonshire Black History Association. http:// www.northant-blackhistory.org.uk

Bracey P. 2010 Perceptions of the contribution of an Irish dimension in the English history curriculum Educational Review 62 (2): 203-213.

Bracey, P.2015. From Home to the Front. World War 1 in the Primary School Classroom. Primary History.no 69: 14-19.

Borko, H., Davinroy, K. Bliem,C. and Cumbo, K. 2004. Changing instructional and assessment practices through professional development. In: Poulson, L. and Wallace, M . Teaching and Learning (Ed) London: Sage, 63-85.

Bradshaw,M. 2009. Drilling down:how one history department is working towards progression in pupils thinking about diversity across years 7, 8 and 9'. Teaching History, no.135:4-12.

Claire, H. 1999. Reclaiming our pasts. Equality and diversity in the primary history curriculum. Stoke: Trentham. http:// www.northant-black-history.org.uk Claire, H. 2007a. Walter Tull: Sport War and challenging adversity (Key Stage 1) Northampton: Northamptonshire Black History Association. http:// www.northant-blackhistory.org.uk 
Claire, H. 2007b. Walter Tull: Sport War and challenging adversity (Key Stages 2 and 3)

Northampton: Northamptonshire Black History Association. http:// www.northant-blackhistory.org.uk

Claire, H. 2007c. Walter Tull. Professional Black Footballer and First Black Officer in the British Army. Northampton: Northamptonshire Black History Association

Codd, J. 2005. Teachers as 'managed professionals' in the global education industry: the New Zealand experience, Educational Review 57(2): 193-206

Corfield, P. 2009. 'Teaching history's big pictures: including continuity and change'. Teaching History, no.136:53-9

DfEE/QCA. 1999. History: The National Curriculum for England Key Stages 1-3. London: Department for Education /Qualifications and Curriculum Authority.

Department for Education. 2013. History Programmes of study for Key Stages 1, 2 and 3.London: Department for Education.

http://media.education.gov.uk/assets/files/pdf/h/history\%2004-02-13.pdf

Field, K., P. Holden, and H. Lawler. 2000. Effective Subject Leadership. London:

Routledge.

Gain, C. and R. George. 1999. Gender, Race and Class in Schooling.Abington: Routledge Farmer

Gillborn, D. 2008 Racism and Education. Coincidence or Conspiracy? London: Routledge Gove -Humphries, A. 2007. From Slavery to Emancipation. Key Stage 3. Northampton:

Northamptonshire Black History Association.

Gove -Humphries, A., and J. Haynes . 2008. Living Memories. Key Stage 2/ 3Northampton: Northamptonshire Black History Association.

Grosvenor, I. 2000. 'History for the Nation': multiculturalism and the teaching of history, J. Arthur, and R. Phillips (ed). Issues in History Teaching. London: Routledge, 148-58.

Grosvenor, I and Myers, K. 2001. Engaging with history after Macpherson. The Curriculum Journal. 12, no.3:275-89

Gunter, H., and P. Thomson.2009. The makeover: a new logic in leadership development in England, Educational Review, 61(4): 469-483.

Helm, T. M. Taylor and R. Davis, 2011. Cameron sparks fury with attack on multiculturalism. The Observer. $6^{\text {th }}$ February: 1

Home Office. 2001. Race Relations Amendment Act 2000.New Laws for a Successful Multiracial Britain. London: Home Office 
Howson, J.(2009) Potential and pitfalls in teaching 'big pictures' of the past. Teaching History.

Teaching History, no. 136: 24-33.

IPC. [n.d] The International Primary Curriculum.

http:// www.internationalprimarycurriculum.com/view_pagecontent.php?resourceid

Johnson,P.2000. Analysis: Thinkers who want to consign our island to history. Daily Telegraph, $10^{\text {th }}$ October: 6 .

Kitson, A., and A. McCully.2005. 'You hear about it for real in school'. Avoiding, containing and risk- taking in the history classroom. Teaching History. no.120:32-37

Kushner, T. 2006. Great Britons: Immigration, History and Memory, ed. K. Burell, and P.Panayi. Histories and Memories. Migrants and their History in Britain. London:

Tauris: $18-34$.

Lang, S. 2011. Letters. London Review of Books. 33. No 7.

http://www.lrb.co.uk/v33/n07/letters

Lee , P and Shemilt, D.2007. New alchemy or fatal attraction? History and citizenship, Teaching History, no. 127:14-19.

Lyndon, D. 2007. Walter Tull: Sport War and challenging adversity (Key Stages 3)

Northampton: Northamptonshire Black History Association. http:// www.northant-black-

history.org.uk

Macpherson, W. 1999. The Stephen Lawrence Inquiry. London: Home Office. http://www.archive.official-documents.co.uk

McGovern, C. 2007. The new history boys. Whelan, R ed. The Corruption of the Curriculum.London: Civitas.

Mycock, A. 2010. The enduring legacy of empire: post-imperial citizenship and national identity(ies) in the United Kingdom, ed. Dimova-Cookson, M. and Stirk, P Multiculturalism and Moral Conflict. London: Routledge

Northamptonshire Black History Association. n.d. Northampton. Northamptonshire Black History Association. http://www.northants-black-history.org.uk/

Northamptonshire County Council (2011) Census: Ethnicity Northamptonshire Analysis. The Authority on Northamptonshire Statistics http://www.northamptonshireanalysis.co.uk/ Parekh, B. 2000. The Future of Multicultural Britain. The Parekh Report. London: Prolific. QCA 2004 History 2003/4 annual report on curriculum and assessment. London: Qualifications and Curriculum Authority. 
QCA. 2007. The Secondary Curriculum Review. Programme of Study: History Key Stage 3. London: Qualifications and Curriculum Authority.

QCDA/DCSF.2010. National Curriculum Primary Handbook. Coventry: Qualifications and Curriculum Development Agency/Department for Children, Schools and Families.

Siblon, J. 2005. Black is also British: An investigation into the needs and opportunities for developing Black History within the school curriculum in Northamptonshire: A Report commissioned by Northamptonshire Black History Project and University College Northampton. Northampton: Black History Project and University College Northampton. http:// www.northant-black-history.org.uk

Tang, S. and P. Lin Choi.2009. Teachers' professional lives and continuing professional development in changing times, Educational Review 61(1):1-18. Traille, K. 2007. 'You should be proud about your history. They made me feel ashamed: teaching history that hurts'. Teaching History no.127:31-7.

Yin, R.K. 2009. Case Study Research: Design and Methods.Thousand Oaks: Sage

Words: 7,691 (7, 174 script, abstract and reference list, 248 Table 1 and 269 Table 2) 